\title{
VIRTUAL AND AUGMENTED REALITY TO EXPLOIT STEM-SKILLS-BASED LEARNING FOR ENGINEERING STUDENTS USING THE TEC21 EDUCATIONAL MODEL
}

\author{
Carlos GONZALEZ-ALMAGUER, Angeles AGUIRRE, Olaf ROMAN, Alejandro ACUÑA, \\ Claudia ZUBIETA and Pedro PEREZ \\ Tecnologico de Monterrey
}

\begin{abstract}
The worldwide confinement due to Covid19 has boosted creativity in academia to develop learning activities with role-playing games and multidisciplinary workshops brought to our students' homes. Tecnologico de Monterrey, like most universities in the world, is delivering classes remotely using internally developed and external platforms designed to continue the practices that were done every day in laboratories, facilities, and visits to companies and institutions.

This document describes the migration of academic activities, designed under the university's Tec21 Educational Model guidelines, to an internet platform that adopts virtual and augmented reality to deliver learning with the same academic quality as the traditional face-to-face classes. Our training partners in industry, government, and not-for-profit organizations can communicate and access the practice activities on the virtual platforms.

The Tecnologico de Monterrey School of Engineering and Design has worked to generate a simulator of an ERP (Enterprise Resource Planning) system based on the educational platform "Tec21 Car Assembler." Using virtual reality, the student can apply the virtual classroom's theoretical learning to practice, guided by an academic figure who collaborates with training partners from companies and institutions associated with Tecnologico de Monterrey to transfer knowledge to students.

Through virtual and augmented reality, the students have been able to interact with the scale car assembly through the EON XR platform, where teachers have designed different lessons based on car assemblies and subassemblies, in this case, Jeep. We are developing our own platform for assembling Meccano designs that can be made by students first using second and third simulations until they can be taken to assembly, using augmented reality and finally, virtual reality.
\end{abstract}

Keywords: Augmented reality, virtual reality, gamification, educational innovation, higher education

\section{INTRODUCTION}

This research is an extension of the work presented in the 2020 edition of E\&PDE [1]. We share the impact of simulations through playful STEAM tools [2], mainly, Meccano developed by students in Industrial Engineering and Design. Beginning March 2020, we were affected globally by the confinement brought about by the COVID-19 virus, so the challenge of this education was elevated. We brought practice activity to the virtual world using a platform that simulates a car assembly plant with virtual and augmented reality.

Virtual reality (VR) focuses on the design, engineering, and research connected with immersive interactive systems. These virtual reality systems synthesize environments or worlds in realistic simulations that are usually rendered with three-dimensional images, sounds, and robust feedback [3]. This type of technology allows us to immerse ourselves in environments and processes altered to our reality, intensifying the experience and imagination, thus boosting our students' research and learning processes.

The use of Virtual and Augmented Reality allows the environment to become interactive, colourful, and three-dimensional. It allows us to create immersive experiences, where the users can witness experiences and events that seem to be real. 
Studies have shown that VR and AR experiences have increased student motivation and helped them acquire research, critical thinking, problem-solving, and communication skills through collaborative exercises. The benefits of VR and AR technology are reflected in our students' results as learning achievements, better learning outcomes, increased motivation and more positive attitudes. They demonstrate emotions of happiness as they "learn through the game"[4].

According to Gartner Inc. (2008) [5], there are various significant emerging technology trends. He highlights the technologies that will significantly affect companies, society, and people in the coming years. These include technologies that enable businesses and society to regain confidence in technology. AR technology is booming exponentially because its use in innovative educational applications in the classroom is increasingly prevalent, allowing students and teachers to "interact" more thoroughly in their activities and the teaching-learning process. In an institutional way, in Tecnologico de Monterrey, we are using the Flexible and Digital Model [6]. It is a challenge-based learning model that integrates innovative teaching strategies and cutting-edge technologies. The model proposes a flexible and digital learning experience that emphasizes content, interaction, learning activities, technological tools, and evaluation.

Various research studies in the educational environment have shown that experiences with emerging technologies such as AR and VR have resulted in the following parameters (in descending order): learning advantages $(43.75 \%)$, motivation $(31.25 \%)$, ease of interaction $(15.63 \%)$, collaboration (18.75\%), low costs $(12.5 \%)$, learning (12.5\%), just-in-time information (12.5\%), in-place learning (9.38\%), student-centred (9.38\%), student care $(9.38 \%)$, enjoyment $(9.38 \%)$, exploration $(12.5 \%)$, increased capacity for innovation $(6.25 \%)$, positive attitude $(6.25 \%)$, awareness $(3.13 \%)$, anticipation (3.13\%), and authenticity (3.13\%) [7].

At Tecnologico de Monterrey, the instrument for measuring the classes' effectiveness was the ECOA, an institution-wide student opinion survey. During the pandemic, this instrument yielded information that our students wanted educational platforms to bring them closer to laboratory and professional practice experiences with training partners. These include goods-and-services companies, civic organizations, and government. Performing projects with them offers our students a more connected real-world experience.

Independently of the ECOAs, we have conducted surveys on the first day of classes since the school period August to December 2020, where we ask the students three fundamental questions to measure their mood:

1. How have you felt about the health situation we are experiencing in the country?

2. How do you feel about online classes?

3. What have you not liked in the online courses that you do not want to be repeated in this class?

We found that most students have emotions of frustration, despair, and sadness about the current situation and require intellectual stimulation through dynamic and disruptive teaching to face challenges and experience their university life as they knew it before confinement.

The safety and health restrictions and confinement due to COVID-19 have led us to design platforms with virtual and extended reality using an ERP simulator designed by this research group. The platforms enable interactions among students, teachers and training partners to improve students' knowledge and develop competencies through simulations of realistic situations encountered in society and companies. This research article describes the methodology for the simulator design and the results obtained so far. Despeisse [20] mentioned that gamification and experiential learning are increasingly used in education as they create an immersive environment to simulate students and promote deeper learning. In industrial engineering education, computer simulation and digital games are commonly used to teach skills in supply chain theories learnt and reflect on the impact of their decisions, also describes that other handson games can also foster the development of professional skills such as leadership, teamwork and communication, in Tec21 educational model is called competencies.

In different universities, mainly IMT [21], many simulators have been developed that can be used on computers, such as the game of beer and fish banks. For the ERP concept SAP has his own simulator. There are many educational strengths in these simulators, which have been used by the industrial engineering department for many years, the weakness is that they are games focused on certain disciplinary skills, such as logistics and decision-making. Our proposal has the educational innovation of simulating several disciplines concurrently, in addition to making use of augmented and virtual reality technology. 


\section{METHODOLOGY}

The research methodology fuses two disciplines, Experiment Design and Design Thinking, to construct the simulator with current ERP platforms (Enterprise Resource Planning) [8]. Figure 1 shows the methodology applied to this research.

The first step in design thinking is empathy. To approach this, we analysed the institutional surveys (the ECOAs) and those applied by the research group in the school periods February-June 2020, Summer 2020, August-December 2020, Winter 2021, and February-June 2021. The surveys gathered students' opinions, which we analysed at the beginning and end of the school period. Doing this allowed us to determine both the mood of the students and their needs.

In the definition part, we used engineering thinking based on the algebra of sets to determine the most critical characteristics that the simulator should have. Among them, we selected the hook, academic rigor, transversal and disciplinary competencies, gamification, technology, and degree of difficulty. Using nominal techniques and interpretive structural modelling, we defined three critical variables: student engagement ("the hook"), academic rigor, and transversal competencies. Having done this, we began to define the parameters for these variables and proposed the experimental design.

Three hypotheses were defined to be tested based on the use of our simulator:

a) That statistically, the students' learning would be high, defining as high a score greater than or equal to 85 points out of 100 .

b) That statistically, the students would develop transversal competencies, evidenced by a rubric to assess learning.

c) That the students would use the simulator on average more than 50 hours in the school period.

Through the experimental design, we could determine the area for which the simulator should be designed. Determining this, we made a prototype that tested five groups (classes) in a sample of 271 students. The final design of the Tec 21 VEP (Virtual Enterprise Planning) was completed after analysing the exit survey results.

\section{DEVELOPMENT}

One of the biggest challenges of distance learning is achieving fun and practical learning. It can be done by integrating new technologies into the learning process [9]. One of these technologies is Augmented Reality (AR). AR is defined as the technology that allows virtual objects to superimpose on the real world so that they seem to coexist with the real-world objects in the surroundings [10]. This technology has already been used in the military, medicine, engineering design, robotics, manufacturing, maintenance and repair applications, consumer design, and psychological treatment, to name just a few [11]. Employing interactive techniques supported by this technology, the user can change the position, shape, or other characteristics of virtual objects (also called augmented components) in ways never before possible.

Various studies have shown the advantages that this technology offers in education. Georgiou \& Kyza [12] investigated whether the impact of immersion in learning in location-based AR environments was influenced by student motivation. The study focused on 135 tenth-graders who used an AR application for environmental science learning. The results showed that the immersion positively impacted domainspecific motivation and cognitive motivation. In turn, the gains in conceptual learning were also positively related to the level of immersion that the students experienced. Mumtaz et al. [13] compared students' learning and motivation using AR technology in blended-learning contexts and the classroom, respectively. Their results showed that using AR positively affected the students' learning experience, elevating their confidence and motivation.

Stoyanova, Kafadarova \& Stoyanova-Petrova [14] employed Mobile Augmented Reality (MAR) applications in teaching practice as an innovative way to transfer knowledge. The results showed that AR technology awakens students' interest in learning content and promotes their cognitive activity, offering a more engaging and amusing educational experience. Salmi, H., Thuneberg, H., \& Vainikainen, M. P. [15] analysed learning through AR technology and its cognitive, motivational aspects in an information-learning context. They found that using AR in education offers advantages for all, particularly for groups that previously showed less success. On the other hand, Ibáñez, Di-Serio, Villarán-Molina, \& Delgado-Kloos [16] examined methods to improve students' focus in meaningful activities. As a result, they observed that students in the experimental group achieved a higher learning level than the control group. 
Given these advantages, we might wonder how to use AR technology in learning activities involving simulations that explore the effects of specific decisions regarding a system's components. Ibáñez, DiSerio, Villarán-Molina, \& Delgado-Kloos [17] investigated the effects of using AR-based simulations on student interactions and learning performance. They found that AR simulations helped students learn the fundamental principles of electricity. Crandall et al. [18] tested an AR game that focused on basic enzymatic kinetics in food chemistry. They found that AR games can be used to provide students with multiple perspectives and contextual learning. They facilitate learning transfer and extend skills and understanding of the game to the real world. Hwang, Wu, Chen, \& Tu [19] proposed competitive gaming in AR to support learning activities. They found that this approach improves students' attitudes and learning achievements.

Gamification boosted the students' interest in the activities. So, we designed the simulator to replicate the manufacture of a Jeep to scale with Meccano parts. It emulated the actual process of a car assembly plant. The simulator was based on an ERP system where students could visualize the interactions among an organization's various departments. The simulations also generated random events such as production line failures or other production problems.

The final design is a flexible model that comes from the customer orders for the different car models assembled. The information enters the software that processes them, which, as a result, suggests production orders and materials purchases. To accomplish production, the users must input the system with the parts' specifications and make the BOM (bill of materials) and the MRPs for each product, with its quality and product-design specifications. The simulator does the transactions through screens (dashboard), making suggestions for decision-making. The student must apply theoretical learning in decision-making. The ultimate goal of using the simulator is to assemble cars with the required quality, obtaining the best margin of utility for which grades are obtained. When the student dominates the theoretical part and, consequently, makes the best decisions in the simulator, he or she obtains higher grades.

The digital part of the VEP virtual assembler interfaces with the EON XR system. Through augmented reality, virtual reality, and 3D graphics, the student explores the components and assembles the product. The activity design is placed in a CANVAS system module where the educational intent is specified. The student is instructed to install both the VEP and EON XR simulator to experience in a virtual environment an assembler's role, analyse real problems, and create models that can abstract that reality and give solutions that are measurable and quantifiable. Also, a training activity was designed for students to become familiar with the AR and VR tools.

The specific learning objectives were defined as follows:

1. Learn to abstract a problematic situation and define problems.

2. Learn how to map a company's information flow and processes and illustrate them in diagrams that synthesize and explain the flows and processes.

3. Define and create databases with the provided information for analysing; develop or obtain sensitive metrics.

4. Build solution proposals with systemic, simultaneous, and forward-looking thinking.

5. Develop resilience in the students to overcome difficulties and arrive at propositions of value.

Also, putting a significant challenge in an activity design in the face-to-face and online courses was crucial. The challenge was implemented in both types of courses at Tecnologico de Monterrey. In the online course, a total of 192 out of $318(60 \%)$ students opted for the car assembly plant called the "Tec21 Car Assembler." Implementing it challenged us much according to the learning objectives mentioned previously, and we counted on the support of the external professors who taught the subject. The development of the activity, the EON-XR tool, the teacher training, and the design application to the students are summarized in Figure 1.

\section{RESULTS}

The students could see the virtual plant's entire operations and experience a virtual learning environment within the assembly plant. Thus, they became familiar with the different products' details, experienced real problems, and created models to propose different measurable and quantifiable solutions. The results of using the VR and AR tools are compiled in Figure 2 for the online class application, where the students could experience live class demonstrations. 

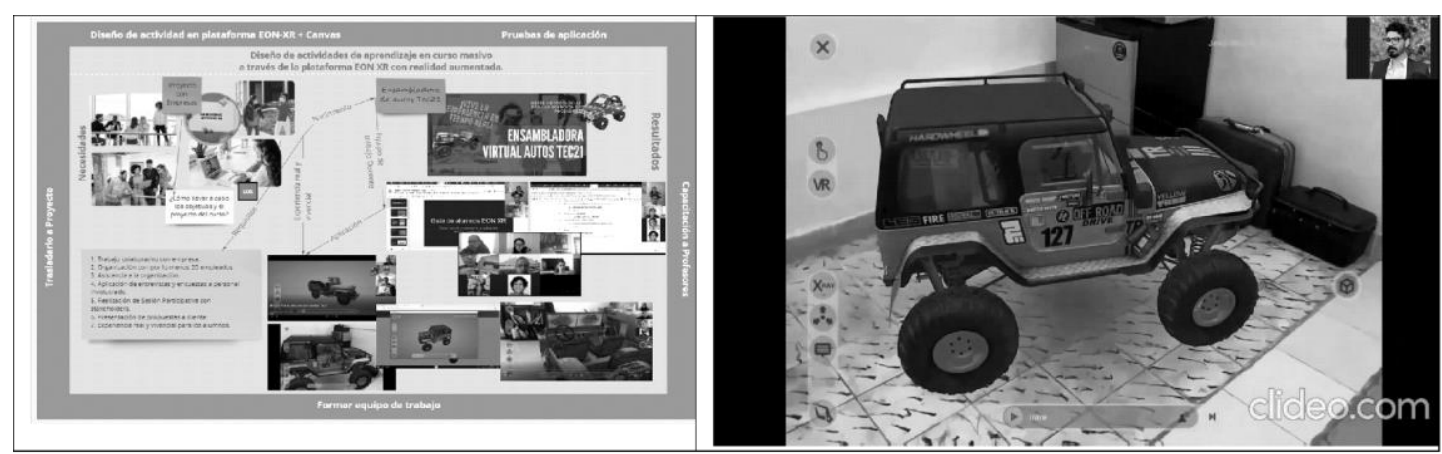

Figure 1. EON-XR tool, teacher training and design application

The results were medium to high grades depending on their experience with the tool in the real-time demonstration. The learning outcomes achieved around 80\% (in presential class) and $81.2 \%$ (online). For the activity design practice, the average grade was $76.2 \%$ (in class) and $73.2 \%$ (online). The achievement of objective parameters $(70.4 \%, 70.2 \%)$, ease of use $(70.6 \%, 70.2 \%)$ and utility of the application $(70.4 \%, 69.4 \%)$ averages were practically similar.

In short, the overall evaluation by those who used AR and VR in real-time was $76.2 \%$, and $74.8 \%$ for online students. The survey and feedback from the EON-XR tool experience only came from students who used the AR and RV app in the online course during the August-December 2020 academic year
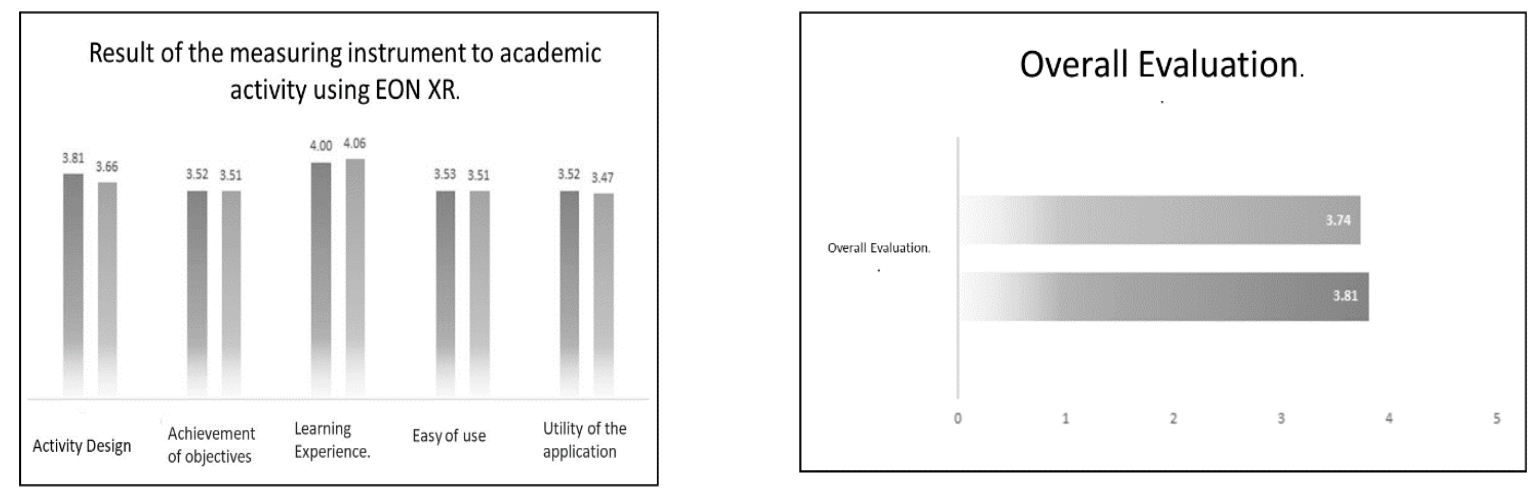

Figure 2. Results of the overall evaluation of the VR and AR tools in the face-to-face and online classes

\section{CONCLUSIONS}

The project addressed the issues of distance education in the Engineering and Design subject for our students through a simulator design. It was potentialized by virtual reality and augmented applications. The institutional student opinion surveys found that their perception of the learning model improved. In the virtual classroom, we could infer the change in the students' mood from what it had been at the start of the school term. In the end, the students motivated by gamification mastered the methodologies studied in the course and achieved higher grades. They also had the opportunity to experience the reality of an assembly plant through augmented reality. It empowered them to manage the day-to-day situations of a real manufacturing plant.

\section{ACKNOWLEDGEMENTS}

The authors would like to acknowledge the financial support of Writing Lab, Institute for the Future of Education, Tecnologico de Monterrey, Mexico, in this work.

The authors would like to acknowledge the financial support of NOVUS 2020, ID 199 an initiative of Tecnologico de Monterrey, Mexico, in the production of this work.

\section{REFERENCES}

[1] The 22nd International Conference on Engineering \& Product Design Education (E\&PDE 2020). Mechatronic Design for Students, Model Based on Industrial Engineering Techniques. VIA University in Herning, Denmark. 10 ${ }^{\text {th }} 11^{\text {th }}$ September 2020. 
[2] Khine M. S. and Areepattamanddil S. (2019) Steam Education Theory and Practice, Emirates College for Advanced Education, Abu Dhabi, United Arab Emirates. Springer Nature Editors New York USA

[3] Çolak O. and Yünlü L. A review on augmented reality and virtual reality in Engineering Education. Journal of Education and Instructional studies in the world. February 2018, Volume: 8 Issue: 1 ISSN: $2146-7463$.

[4] Häfner P., Häfner V., and Ovtcharova J. (2013) Teaching methodology for virtual reality practical course in engineering education. Procedia Computer Science.

[5] Gardner L. "Using a spreadsheet for active learning projects in operations management" INFORMS Transactions on Education, vol. 8, no. 2, pp. 75-88, 2008.

[6] Tecnologico de Monterrey, Transforma tu curso a flexible digital para la continuidad académica, https://innovacioneducativa.tec.mx/transforma-flexible-draft/modelo-flexible-digital/ [Accessed on 202129 th January]

[7] Akçayır M. and Akçayır G. Advantages and challenges associated with augmented reality for education: A systematic review of the literature. Educational Research Review, vol. 20, p. 1-11, 2017.

[8] Shirley M., Stretch-Stephenson H., Houston R., and Germano M. A. Integrating Technology into Marketing Courses via SAP Enterprise Resource Planning (ERP) System. Journal of Business and Economics, ISSN 2155-7950, USA March 2015, Volume 6, No. 3, pp. 424-43

[9] Dietrich N., Kentheswaran K., Ahmadi A., Teychené J., Bessière Y., Alfenore S., Laborie S., Bastoul D., Loubière K., Guigui C. et al. Attempts, successes, and failures of distance learning in the time of COVID-19. Journal of Chemical Education, vol. 97, p. 2448-2457, 2020.

[10] Akçayır M. and Akçayır G. Advantages and challenges associated with augmented reality for education: A systematic review of the literature. Educational Research Review, vol. 20, p. 1-11, 2017.

[11] Kesim M. and Ozarslan Y. Augmented reality in education: current technologies and the potential for education. Procedia-social and behavioural sciences, vol. 47, p. 297-302, 2012.

[12] Georgiou Y. and Kyza E. A. Relations between student motivation, immersion and learning outcomes in location-based augmented reality settings. Computers in Human Behaviour, vol. 89, pp. 173-181, 2018.

[13] Mumtaz K., Iqbal M. M., Khalid S., Rafiq T., Owais S. M., and Al Achhab M. An E-assessment framework for blended learning with augmented reality to enhance the student learning. Eurasia Journal of Mathematics, Science and Technology Education, vol. 13, p. 4419-4436, 2017.

[14] Stoyanova D., Kafadarova N. and Stoyanova-Petrova S. Enhancing elementary student learning in natural sciences through mobile augmented reality technology. Bulgarian Chemical Communications, vol. 47, p. 532-536, 2015.

[15] Salmi H., Thuneberg H. and Vainikainen M.-P. Making the invisible observable by Augmented Reality in informal science education context. International Journal of Science Education, Part B, vol. 7, p. 253-268, 2017.

[16] Ibáñez M.-B., Di-Serio Á., Villarán-Molina D. and Delgado-Kloos C. Augmented reality-based simulators as discovery learning tools: An empirical study. IEEE Transactions on Education, vol. 58, p. 208-213, 2014.

[17] Ibáñez M.-B., Di-Serio A., Villarán-Molina D., and Delgado-Kloos C. Support for augmented reality simulation systems: The effects of scaffolding on learning outcomes and behaviour patterns. IEEE Transactions on Learning Technologies, vol. 9, p. 46-56, 2015.

[18] Crandall P. G., Engler III R. K., Beck D. E., Killian S. A., O'Bryan C. A., Jarvis N., and Clausen E. Development of an augmented reality game to teach abstract concepts in food chemistry. Journal of Food Science Education, vol. 14, p. 18-23, 2015.

[19] Hwang G.-J., Wu P.-H., Chen C.-C., and Tu N.-T. Effects of an augmented reality-based educational game on students' learning achievements and attitudes in real-world observations. Interactive Learning Environments, vol. 24, p. 1895-1906, 2016.

[20] Despeisse M. (2018). Games and simulations in industrial engineering education: a review of the cognitive and affective learning outcomes, Proceedings of the 2018 Winter Simulation Conference, 4046-4057. Doi: 10.1109/WSC.2018.8632285.

[21] Fishbanks: A Renewable Resource Management Simulation.https://mitsloan.mit.edu/teachingresources-library/fishbanks-a-renewable-resource-management-simulation. Accessed on $20211^{\text {st }}$ May 